\title{
UMA INVESTIGAÇÃO DISCURSIVA ACERCA DE CALABAR - O ELOGIO DA TRAIÇÃO: O HUMOR COMO EVENTO POLIFÔNICO.
}

Manuella Felicíssimo (UFMG)

\section{Introdução}

Este estudo tem por objetivo fazer uma reflexão, sob a luz da análise do discurso da linha francesa, acerca do humor na literatura, mais precisamente, da linguagem transgressiva que se instaura no discurso literário-teatral em decorrência de fenômenos como ironia e paródia. Esse enfoque será norteado a partir da peça Calabar - o elogio da traição (1973), de Chico Buarque e Ruy Guerra. A análise será orientada a partir da hipótese de que a ironia, os personagens caricaturais e a paródia são engendrados na obra de forma a constituir uma espécie de literatura da transgressão - termo aqui entendido no sentido de subversão de uma certa ordem social e também como um jogo linguageiro, que traz para a cena teatral vozes outras que não somente as dos personagens.

O conceito riso também será abordado, ainda que de maneira superficial, mas o suficiente para se entender a linguagem humorística como algo singular que apela para a participação do leitor-público e que se constitui, na peça, como uma zombaria dos aspectos que são colocados em foco pelo humor.

Por fim, trilhando o percurso intradiscursivo e interdiscursivo, a análise tentará apontar como o humor é instaurado na obra e como ele refrata parte da realidade e do ideário político da década de 1970.

\section{A heterogeneidade discursiva}

Para Maingueneau (1989), o discurso seria constituído de maneira heterogênea. $\mathrm{O}$ autor fala de heterogeneidade mostrada e heterogeneidade constitutiva no discurso, sendo a primeira manifestações explícitas na superfície do 
enunciado, e a segunda manifestações que não são marcadas lingüisticamente, mas que podem ser recuperadas no interdiscurso. É a partir desse pressuposto que se considera a peça Calabar, buscando observar como o contexto de produção da peça se faz presente no texto teatral através de diversas vozes: que se entrecruzam, se citam e se refutam. Em outras palavras, a peça se utiliza do discurso da História (ano de 1635) e o coloca no discurso da década de 1970, através da ironia e da paródia. Dessa maneira pode-se dizer que os autores enunciam uma voz que não é unicamente a deles e que corresponde a uma resposta ao Regime Ditatorial (1970). Nesse sentido, a noção de heterogeneidade constitutiva do discurso é fundamental nesse estudo, pois, de acordo com Authier-Revuz (2004), esse conceito se caracteriza como uma

“ancoragem necessária no exterior do lingüístico: e isso, não somente para as formas que parecem oscilar facilmente devido às modalidades incertas de seu resgate, mas, fundamentalmente, para as formas mais explícitas, mais intencionais, mais delimitadas da presença do outro no discurso" (2004:22).

Com base na noção dos dois autores acima, pode-se dizer então que Calabar constitui-se como um discurso heterogêneo, cujas vozes podem aparecer direta ou indiretamente, sempre como reflexo de determinadas implicações ideológicas. No tocante ao elemento humorístico (ironia, paródia e caricatura ${ }^{1}$ ), será entendido no decorrer do trabalho, como ele funciona como um elo entre os espaços intradiscursivo e interdiscursivo, e também entre os dois discursos que se tem na peça, o da História do Brasil Colonial (representado) e o do Brasil Ditatorial (aludido).

\section{A peça através da paródia e da ironia}

A peça Calabar - o elogio da traição retoma o ano de 1635, momento da invasão holandesa ao nordeste do Brasil Colônia, transformando esse "pedaço" da história num palco onde são manifestadas, de forma irônica, críticas que implicam questões como pátria e nacionalidade. A partir do trágico e do cômico, Chico Buarque e Ruy 
Guerra inserem no âmago teatral uma voz politizada, carregada de ideologias e de repulsa ao governo autoritário do Brasil da década de 1970.

Mathias de Albuquerque, governador português, dá início à perseguição ao grande traidor, Calabar, que no ano de 1632 teria passado a lutar pelos holandeses, deixando os portugueses - pelos quais antes lutara. Mathias, juntamente com Camarão, Bárbara, Dias, Souto - todos personagens históricos -, e Anna (personagem fictícia) representam, nesse teatro musical, as conseqüências do desastroso conflito entre Portugal e Holanda - potências interessadas no controle do sistema de produção do açúcar no Brasil Colônia.

As investidas da Holanda começam em 1630 sem muito sucesso. No entanto, a partir do momento em que Calabar passa a lutar pelos holandeses, eles alcançam conquistas importantes.

Mathias de Albuquerque captura Calabar, que é morto e esquartejado. O peso de tal acontecimento traz inúmeras reflexões a respeito da aparente traição desse homem brasileiro. O Brasil Colônia torna-se, então, lugar de lirismo, de contradição e, principalmente, de traição - tema instigado pela peça, mas não concluído ou sequer julgado.

Já desse início cabe retomar a peça no seu contexto de produção, a década de 1970. Assim, ela se apresenta provocativa, agressiva e fortemente comprometida com as questões políticas e sociais. Nas palavras de Fernando Peixoto, diretor de Calabar, a peça surpreende pelo

"atualizado deboche crítico, fundamentado num confronto realista com temas essenciais de nossa existência de nação socialeconômica-política-culturalmente ainda colonizada num tímido mas empenhado esforço de construção de uma democrática cultura nacional-popular". (Peixoto, apud Buarque \& Guerra, 1994:XXV).

Sendo assim, Calabar tem no seu âmago representações de valores, de uma ideologia. Para o círculo de Bakhtin (apud Brait, 2005), ideologia corresponde a reflexos das interpretações da realidade social e natural, sendo que estas existem e são expressas em qualquer forma sígnica, não sendo pertinente a noção de qualquer 
signo fora da ideologia.Na leitura que aqui se faz acredita-se que é justamente o humor que canaliza a ideologia difundida pela obra.

É através da ironia e da paródia ${ }^{2}$, recursos linguageiros, que a peça conjuga dois tempos distintos, o Histórico e o Contemporâneo (de 1970), apelando para o riso do leitor-expectador. Esse riso é o resultado de processo comunicativo bemsucedido, uma vez que para rir é preciso compreender o que é proposto; além disso, o riso é também um símbolo de cumplicidade. Com base nisso, o leitorpúblico é nessa peça algo fundamental, não somente um sujeito passivo, mas alguém que percebe e aceita o caráter ambíguo da linguagem e se coloca de acordo com ela; principalmente, cumprindo o apelo à zombaria, uma ação que pune aquilo que é colocado e, geralmente, acentuado no alvo do humor. A peça se torna, então, dialógica (Bakhtin, 2006). O riso, nesse sentido, seria a não-ordem, um desvio dos padrões estabelecidos: seja com relação ao padrão da linguagem ou no que diz respeito ao comportamento social e cultural.

Assim, engendrada pela ironia, Calabar é uma peça que retoma a história do Brasil a partir da paródia. Os acontecimentos encenados se apóiam em fatos que realmente aconteceram, mas de modo algum podem ser entendidos pelo viés da veracidade. A História do Brasil Colonial (o momento da invasão holandesa em Pernambuco) é o pano de fundo para a encenação dos personagens e é distorcida pelo trato paródico. Assim, a peça lança uma proposta de um olhar diferente para a realidade brasileira: a partir da paródia, surge um outro discurso, mais do que parafrasear, a peça vai além, inverte os sentidos. Pode-se dizer que a História do Brasil é imitada, mas de modo a acentuar aspectos depreciativos. Conforme assinala Propp (1992) "de modo a ocultar ou negar o sentido interior daquilo que é submetido à parodização" (p.84-85). A peça, pretensiosamente debochada, alcança o tom humorístico. Uma vez submetida à paródia, a história do duelo Portugal X Holanda torna-se menos relevante. Ocultada, ela se revela como um propósito de contemplar outras questões, que surgem através da ironia. Questões como nacionalidade e traição, por exemplo. 
Para D.C Muecke (1995) ironia designa algo evasivo, reservado, algo que causa uma impressão, que não dá respostas diretas. Ironia seria também dizer o contrário daquilo que se diz. Esse fenômeno se caracteriza como uma atividade lingüística cuja essência está na ocultação da responsabilidade do sujeito que é irônico, isto devido ao fato de a ironia ser, a princípio, uma sugestão. Ela se efetiva apenas quando alcança o sujeito que atribui sentido. Para tal, é necessário um compartilhamento de conhecimentos ideológicos, sociais e culturais a partir dos quais se dá o sentido irônico.

O enunciado irônico é de natureza polifônica. Nele, pelo menos, duas vozes ecoam. E, por se realizar no outro, é também dialógico, não se encerrando em si mesmo (Bakhtin, apud Brait, 2005). Assim, o sujeito diante da ironia, não apenas vê a peça, mas também se vê nela, da mesma forma que o locutor se esconde, mas não deixa de se apresentar.

"O que caracteriza a polifonia é a posição do autor como regente do grande coro de vozes que participam do processo dialógico. Mas esse regente é dotado de um ativismo especial, rege vozes que ele cria ou recria, mas deixa que se manifestem com autonomia e revelem um homem no outro (...)". (Bezerra, in: Brait, 2005:194).

O fenômeno irônico em Calabar, portanto, estabelece a interação entre as vozes das personagens, as do autor e também as do público, fazendo com que o sujeito diante da peça se veja nela projetado. O leitor-público participa do espetáculo compreendendo e suprindo a proposta irônica, é ele quem preenche os não-ditos da ironia.

\section{Calabar e o gênero sério-cômico}

Bakhtin (1998), ao abordar o gênero sério-cômico, afirma que esse já teria aparecido na Antiguidade clássica, oriundo de uma diversidade de gêneros. Os antigos colocavam no campo do sério-cômico os mimos de Sófron (literatura que descreve festas na Grécia antiga), a poesia bucólica, a sátira menipéia e outros. Esses gêneros, conforme a abordagem de Bakhtin, seriam opostos à epopéia, à 
tragédia, à história e à retórica. $\mathrm{O}$ autor concebe o gênero sério-cômico a partir de uma cosmovisão carnavalesca, elemento capaz de transformar a realidade.

No universo sério-cômico não existe um só gênero, mas vários gêneros dialogando entre si. O cômico, por exemplo, lugar dos fracassos humanos e das falhas, é mesclado na peça de modo a se confundir com o sério. Desse modo, Calabar torna-se distante da figura lendária do herói, pois é submetido aos deslizes humanos. Isso confere à peça maior vitalidade, maior poder de tocar na realidade, de subvertê-la. À medida que Calabar, personagem histórico, é colocado de forma que seu ato de heroísmo seja distinto da noção clássica de herói, estamos diante de uma peça cuja constituição se dá aos moldes do universo sério-cômico: familiaridade, humanização e riso arquitetam a peça. É dessa forma que o texto Calabar coloca no plano da História do Brasil questões que tocam a realidade de forma profunda. A partir do trato humorístico, os autores criaram um texto que tem momentos hilários numa peça fundamentalmente trágica, e que contemplam os traços humanos, aliás, os mais indicativos das fraquezas do homem.

\section{Calabar e a linguagem da transgressão}

A peça tem início com o personagem Frei cantando Miserere nobis. Enquanto o Frei exclama: Agnus Dei qui tollit peccata mundi, os Moradores respondem: Miserere nobis. Esta última expressão latina pode ser traduzida como "Tende piedade de nós”. Esse canto é uma parte do rito católico no qual há uma auto-avaliação e pedido de perdão pelos erros cometidos. É também o momento em que o cristão se coloca pequeno e miserável diante de Deus, apelando por compaixão. Nesse trabalho, acredita-se, que este inicio já inaugura o teor da peça como um todo, o teor ambíguo. Quem lê toda a peça percebe que o que menos importa é o rito católico em si, mas o que ele reporta: a uma subversão do discurso religioso, servindo para aludir à condição miserável que os personagens da peça experimentam. Seguido ao canto de piedade, pode ser constatado um jogo com as palavras da sentença Miserere nobis: miserê/ 'Renó/ bis/ misere/ renobis/ 
misererenobis. (Buarque \& Guerra, 1994:02). Nessa passagem, tem-se a ocorrência da ironia, uma vez que o discurso religioso é submetido à zombaria. Já no espaço intradiscursivo, percebe-se marcadamente a incongruência do enunciado. Assim, se instaura uma distância entre o discurso "original" e o discurso reproduzido na peça, pois a reprodução do mesmo não ocorre com o propósito de se efetivar uma adesão ao discurso reproduzido. Nota-se que o locutor, via ironia, propõe um estatuto de co-enunciador ao leitor, pois este percebe e aceita esse fenômeno.

Ao longo do trabalho será possível notar que as personagens são submetidas ao grotesco; esvaziadas de qualquer moralismo ou autoridade que nelas estejam representadas. O desprestigio a que são submetidos revela um propósito caricatural: a acentuação proposital das imperfeições de caráter. A passagem abaixo, um diálogo entre Mathias, governador português e o Holandês ${ }^{3}$ demonstra como isso se dá na peça:

Mathias: Preciso...(começa a se contorcer em cólicas) cagar.

O Holandês: Ah, a Road Loop! Temos coisa melhor. Referindo-se ao formado das fezes. (Buarque \& Guerra, 1994:25).

Essa situação coloca os personagens numa posição de completo declínio, a partir da ampliação dos aspectos depreciativos. Esse comportamento é algo transgressivo, pois corrompe a imagem séria que as autoridades. Mais uma vez o leitor é um co-enunciador, aceita a deturpação da imagem, colabora com ela, graças ao espaço autorizado pela caricatura. Assim, a inadequação da cena se torna o sentido em si.

A agressividade que é instaurada nesse enunciado se concretiza através da recorrência a uma série de conhecimentos prévios, tanto lingüísticos como culturais: lingüisticamente fezes é conhecida também como merda, no linguajar popular. Tem valor pejorativo, designa indignação, coisa desprezível. Quanto à ação desenvolvida pelos personagens, é culturalmente inconcebível. Assim, a ação se torna caricatural e o caráter de inferioridade é instaurado. Nesse trecho se pode 
notar o poder destrutivo do cômico, ele corrompe a seriedade que constitui esses personagens.

Outra cena de teor transgressivo é o momento em que o Frei entra em com folhas de bananeira perguntando a Mathias e ao Holandês: - Terminaram? (Buarque \& Guerra, 1994:28). Essa cena elucida a submissão da Igreja às lideranças de Portugal e Holanda. Fica claro que o rebaixamento da linguagem e os gestos toscos conferem o caráter cômico e transgressivo da peça. A linguagem se torna livre de polidez e os valores culturais e morais são submetidos ao desvio da norma, do padrão. Esse elemento intradiscursivo reporta para o interdiscurso: a intenção de debochar e acentuar a crítica feita às autoridades políticas e religiosas. O locutor propõe uma ação não convencional que, por sua vez, produz um efeito no interlocutor. Esse efeito não pode ser previsto, mas, pelo espaço no qual o enunciado se dá, conduz-se ao esperado: o riso, o deboche. Pode-se dizer que, nesse momento, se efetiva um contrato:

"inter e intradiscursivo, por parte do enunciatário, e inclui a compreensão do conjunto de contradições que constituem o interdiscurso (as quais são parcelas da heterogeneidade constitutiva do discurso) e do conjunto de percursos semânticos orgânicos do intradiscurso (os quais são parcelas da diversidade intradiscursiva)" (Faria, 2000:108-109).

Sendo assim, mesmo existindo um desvio do convencional, o sentido irônico é, mais uma vez, compreendido, pois a própria proposta jocosa o sustenta. Até aqui se pode notar a presença do elemento caricatural e do teor de protesto veiculado através dele, bem como a necessária participação do leitor-público para a atribuição do sentido construído. Notou-se também que o "Eu" (locutor) se esconde atrás do fenômeno humorístico, fazendo-se existir de maneira indireta e implícita, mas não menos contundente.

O discurso da História, como fora dito, é parodiado em Calabar. A paródia implica, necessariamente, a recorrência a um discurso e a inauguração de outro. O outro discurso é o discurso irônico, de caráter combativo, que instaura um 
desequilíbrio, uma quebra da expectativa do que seria esperado de um relato histórico.

O leitor-público é situado no discurso da história através de diversas linguagens, tanto a verbal quanto a visual (através do cenário e do figurino). A passagem abaixo permite compreender como esse discurso é inserido na peça.

Frei: Era o Brasil, antes da chagada dos holandeses, a mais deliciosa, próspera, abundante, e não sei se me adiantarei muito se disser a mais rica de quantas ultramarinhas o Reino de Portugal ter debaixo de sua coroa e cetro. (Buarque \& Guerra, 1994:02).

Esse enunciado é proferido pelo Frei no inicio da peça e situa o leitor no contexto histórico do século XVII. A junção entre o discurso da história e o discurso do presente da década de 1970 é estabelecida também a partir das músicas que são apresentadas na peça: "Vence na vida quem diz sim", "Tatuagem" e "Elogio da Traição" são algumas delas. Uma vez na peça, elas dialogam com o discurso histórico e, por conseqüência, modificam esse discurso, atualizando-o e trazendo-o para a contemporaneidade. Tem-se um discurso no outro, o estabelecimento de um discurso novo, sendo que é neste que ocorre a apreciação da enunciação anterior (Bakhtin, 2006). Existe uma inter-relação estabelecida entre os dois discursos, não há uma fidelidade ao contexto histórico (Discurso da História), mas uma mescla entre ele e o contexto de produção da peça.

O tema da traição é trazido do contexto histórico para o contexto presente, e também funciona como um elo entre os dois tempos. Todos os personagens experimentam trair - inclusive a peça é um elogio à traição. Calabar atreveu-se a mudar de lado, traindo os portugueses. $\mathrm{Na}$ passagem abaixo Souto, um soldado explica para Bárbara (companheira de Calabar) o porquê de sua própria traição.

Souto: Motivo? Motivo, como? Eu não tenho motivo sequer para estar na guerra. (...). Por que o holandês? Não sei. Vai ver gostei do colorido. (...). Achei normal me bandear com todo o batalhão de flamengos pro lado dos portugueses, porque os portugueses estavam pagando em dia (...). Tornei a mudar outras vezes, por acaso, por carne-de-sol, por dívida de jogo, por questão de mulher (...). (Buarque \& Guerra, 1994:53-54). 
Lutar pelos portugueses ou pelos holandeses pode ser entendido como uma traição, uma vez que não se luta pelo Brasil. Quanto ao discurso da História, ele nos conta que durante este duelo, era recorrente e até comum a adesão ora à Holanda, ora a Portugal, e que, geralmente, a escolha era determinada por interesses econômicos.

Esse tema (traição) é problematizado quando trazido para a cena enunciativa do período de 1970. Sabe-se que manifestações contrárias à ideologia autoritária desse período eram consideradas traição à pátria, mas o tema, nesse contexto (na peça teatral), pode ser relativizado. Com relação ao período do regime militar, "quem traiu e quem traía? Quem dizia não quando deveria dizer sim?". Essa correspondência interdiscursiva pode ser feita tendo em vista a relativização ou a reescritura do papel de Calabar na História. A peça resgata essa personagem e a constrói de maneira diferente do ponto de vista de sua imagem na História. Calabar, de traidor, passa a ser representado pelo viés dos motivos que o levariam a trair, o que confere, dependendo da perspectiva, até mesmo um caráter de herói. Isso pode ser observado na passagem abaixo, momento em que Nassau se prepara para deixar o Brasil.

(Off)

Tu não morreste em vão.

Eis, talvez, um estranho epitáfio

dirigido a estranha gente

de um estranho continente

de contorno incerto

num mapa de imaginação.

Tu não morreste em vão, repito,

aqui deste meu porto

como um gesto de conforto

a algum estranho herói

de contorno incerto

no porto de um povo de imaginação 
(Buarque \& Guerra, 1994:61).

Além do tema da traição, que pode remeter ao contexto do Brasil Ditatorial, tem-se também uma possível alusão ao caráter autoritário e opressor do aparelho estatal militar. A passagem abaixo pode representar esse ponto de vista.

Consultor: "Silêncio... Escrivão não sente. De agora em diante, neste Brasil, escrivão escreve. Assim como estudante estuda, censor censura, ator atua, etc...etc...etc...” (Buarque \& Guerra, 1994:118).

$\mathrm{Na}$ leitura que aqui se faz o enunciado acima pode ser reportado para o conjunto das manifestações ideológicas do Brasil ditatorial. A palavra censura talvez seja a mais explícita; mas também o são o caráter de ordem do enunciado e o paralelismo entre as palavras estabelecendo o sentido de restrição. Mais uma vez nota-se um discurso no outro, o que é enunciado e tem seu sentido no contexto da peça (História) e a possível extrapolação para a conjuntura do período militar.

Uma outra passagem que pode reforçar o que vem sendo dito a respeito da presença de um discurso no outro é o trecho da música "Elogio da traição", cantada no final da peça por todos os personagens.

O que é bom para a Holanda é bom pro Brasil

O que é bom para a Luanda é bom pro Brasil

O que é bom pra Espanha é bom pro Brasil

O que é bom pra Alemanha é bom pro Brasil

O que é bom pro Japão é bom pro Brasil

O que é bom pro Gabão é bom pro Brasil

O que é bom pro galego é bom pro Brasil

O que é bom pro grego é bom pro Brasil

O que é bom pra troiano é bom pro Brasil

O que é bom pra baiano é bom pro Brasil

O que é bom pra inglês é bom pro Brasil

O que é bom pra vocês é bom pro Brasil

O que é bom pra mamãe é bom pro Brasil 
O que é bom pro neném é bom pro Brasil

O que é bom pra fulano é bom pro Brasil

O que é bom pra (...) é bom pro Brasil

O que é bom pra (...) é bom pro Brasil

(...)

(Buarque \& Guerra, 1994:119-120).

Nessa música pode-se ler a crítica à abertura política do Brasil aos interesses internacionais. O que, aliás, pode ser reportado muito mais para o momento do período ditatorial militar do que para o período do Brasil Colônia. A citação de nome de países, e a hierarquização que vai sendo "diluída" até o fim da música, evidenciam a ironia presente nesse enunciado. A apreciação desfavorável a essa condição é observável nos espaços intra e interdiscursivo.

Nota-se que a interação de um discurso com outros é fundamental e constituinte da peça, inclusive basilar para que se dê a ironia e paródia, tal como aqui se tem observado. A recuperação do discurso-outro ocorre, na grande parte da peça, como uma alusão, recuperada no território exterior à linguagem. Esses outros discursos que se fazem presentes configuram a heterogeneidade discursiva.

"As formas de convocação do já-dito funcionam como marcas observáveis de heterogeneidade que, manifestando-se sobre o fio do discurso, produzem rupturas e fornecem não apenas a dimensão de outros discursos, de exteriores que se intrometem no interior discursivo, mas também informações sobre o sujeito, sobre o enunciador". (Brait, 1996:108).

Para Brait (1996), fundamentada em Authier-Revuz, as dimensões sócioideológica e também a psicanalítica (relativa ao imaginário) são constituintes e se fazem presentes na materialidade discursiva. Isso posto, pode-se dizer que a acentuação dos aspectos negativos, de forma a depreciar a imagem que determinados personagens trazem em si, constituem uma manifestação linguageira na qual está depositada a parte da estrutura política, social e cultural do Brasil da década de 1970. Ao transgredir a imagem das autoridades e a própria História, bem como recuperá-la e subvertê-la à conjuntura ditatorial, os autores se fazem 
presentes e, através deles, toda a transitoriedade daquele período. Pela linha que até aqui se tem seguido, esses aspectos levantados são possíveis de serem elencados graças ao espaço interdiscursivo.

Conforme assinalara Authier-Revuz (2004), “o lugar 'do outro discurso' não é ao lado, mas no discurso. Isso posto como lei constitutiva do tecido de todo discurso (...)" (p.37). Os discursos outros que se fazem presentes em Calabar são veiculados, na perspectiva deste trabalho, através do humor - sério-cômico, como fora dito -, que canaliza a ideologia de manifestação de repulsa e contrariedade a qualquer colonialismo, seja ele político, cultural, econômico, e em qualquer âmbito social.

\section{Considerações finais}

Foi abordada neste trabalho a relação estreita entre o humor (ironia, paródia e caricatura) e o interdiscurso, demonstrando como a peça Calabar faz referência a dois planos enunciativos distintos: um calcado no discurso da História (ano de 1635) e o outro relativo ao contexto político e social do Brasil da década de 1970. Verificou-se que o tom humorístico reivindica uma relação de cumplicidade com o leitor-público, uma vez que a duplicidade da ironia e a inversão de sentidos da paródia só são compreendidas quando há um compartilhamento de conhecimentos ideológicos, políticos, culturais etc. entre aquele que enuncia e o enunciatário. Notou-se também que a peça é constituída a partir de diversas vozes: as dos autores (que se escondem atrás da ironia), as da memória histórica, as dos personagens e, ainda, as do próprio público, uma vez que este pode se reconhecer e se ouvir falar neste emaranhado de vozes. Conclui-se, então, que os elementos interdiscursivos são fundamentais nesse fenômeno de linguagem cuja existência está na contradição e na relação de um discurso com o outro, que se dá ora de maneira direta, ora de maneira indireta, reiterando e refutando discursos produzidos ao longo da História. 


\section{Notas}

${ }^{1}$ A noção de caricatura é entendida neste trabalho como uma acentuação dos aspectos negativos que se apresentam de maneira grotesca e cômica.

${ }^{2}$ A paródia é aqui entendida como um elemento que busca a inversão dos sentidos produzidos no discurso original, providos de um teor irônico. O efeito pretendido é a zombaria, efeito caricatural, que ultrapassa os limites da paráfrase, inaugurando, assim, um novo paradigma. (Sant'Anna, 1985).

${ }^{3}$ Esse personagem representa a autoridade holandesa, e é assim denominado na peça, de maneira genérica, simplesmente como Holandês.

\section{Referências Bibliográficas}

AUTHIER-REVUZ, J. Heterogeneidade mostrada e heterogeneidade constitutiva: elementos para uma abordagem do outro no discurso. In: _ـ Entre a transparência e a opacidade - um estudo enunciativo do sentido. Porto Alegre: EdiPUCRS, 2004. p.11-80.

BAKHTIN, M. Marxismo e filosofia da linguagem: problemas fundamentais do método sociológico da linguagem. 12ª ed. São Paulo: Hucitec, 2006.

. Questões de literatura e estética - a teoria do romance. $4^{a}$ ed. São Paulo: Hucitec, 1998.

BEZERRA, P. Polifonia. In: BRAIT, B. (org.). Bakhtin - conceitos-chave. São Paulo: Contexto, 2005. p. 191- 200.

BRAIT, B. (org.). Bakhtin - conceitos-chave. São Paulo: Contexto, 2005.

. Ironia em perspectiva polifônica. Campinas, SP: Editora Unicamp, 1996. Coleção Viagens da Voz.

BUARQUE, Chico \& GUERRA, Ruy. Calabar - o elogio da traição. 15ª ed. Rio de Janeiro: Civilização Brasileira, 1994.

FARIA, A. A. M. Metáfora, metonímia e contrato discursivo em Germinal, de Zola. In.: MARI, H. (org.). Categorias e práticas de Análise do Discurso. Belo Horizonte: Núcleo de Análise do Discurso. FALE-UFMG, 2000. p.107-123.

FIORIN, J. L. Linguagem e ideologia. São Paulo: Ática, 1988.

MAGALD, S. Panorama do teatro brasileiro. $3^{a}$ ed. São Paulo: Global Editora, 1997.

MAINGUENEAU, D. A heterogeneidade mostrada. In: Novas tendências em Análise do Discurso. Campinas: Pontes, 1989. p.75-110. 
Do discurso ao interdiscurso. In: Novas tendências em Análise do Discurso. Campinas: Pontes, 1989. p.111-126.

MUECKE, D.C. Ironia e o irônico. São Paulo: Perspectiva, 1995.

PROPP, V. Comicidade e riso. São Paulo: Ática, 1992.

SANT’ANNA, A.R. Paródia, paráfrase \& Cia. São Paulo: Ática, 1985. 